\title{
Clopidogrel and Proton Pump Inhibitor (PPI) Interaction: Separate Intake and a Non-Omeprazole PPI the Solution?
}

\author{
S. Kenngott ${ }^{1}$, R. Olze ${ }^{1}$, M. Kollmer ${ }^{1}$, H. Bottheim ${ }^{1}$, A. Laner ${ }^{2}$, E. Holinski-Feder ${ }^{2}$, M. Gross ${ }^{1}$ \\ ${ }^{1}$ Internistische Klinik Dr Müller, München, Germany, \\ ${ }^{2}$ Medizinisch-Genetisches Zentrum MGZ, München, Germany
}

\begin{abstract}
Background: Dual therapy with aspirin and clopidogrel increases the risk of gastrointestinal bleeding. Therefore, co-therapy with a proton pump inhibitor (PPI) is recommended by most guidelines. However, there are warnings against combining PPIs with clopidogrel because of their interactions with cytochrome P450 isoenzyme 2C19 (CYP2C19).

Methods: The effects of the combined or separate intake of $20 \mathrm{mg}$ of omeprazole and $75 \mathrm{mg}$ of clopidogrel on the clopidogrel-induced inhibition of platelet aggregation were measured in four healthy subjects whose CYP2C19 exon sequences were determined. The effects of co-therapy with $10 \mathrm{mg}$ of rabeprazole were also examined.

Results: Two subjects showed the wild-type CYP2C19 sequence. The concurrent intake of omeprazole had no effect on clopidogrel-induced platelet inhibition in these subjects. Two subjects were heterozygous for the *2 allele, with predicted reduced CYP2C19 activity. One of them was a clopidogrel non-responder. In the second heterozygous subject, omeprazole co-therapy reduced the clopidogrel anti-platelet effect when taken simultaneously or separately. However, the simultaneous intake of rabeprazole did not reduce the clopidogrel effect.

Conclusion: The clopidogrel-PPI interaction does not seem to be a PPI class effect. Rabeprazole did not affect the clopidogrel effect in a subject with a clear omeprazole-clopidogrel interaction. The separate intake of PPI and clopidogrel may not be sufficient to prevent their interaction.
\end{abstract}

Key words: Proton Pump Inhibitors, Drug Interactions, Clopidogrel, Omeprazole, Rabeprazole

\section{INTRODUCTION}

Dual anti-platelet therapy with aspirin and a thienopyridine (mainly clopidogrel) is recommended in the guidelines of national and international cardiology societies for patients with acute coronary syndrome and/or percutaneous coronary interventions. This combination is usually prescribed for up to one year. Therefore, the number of patients treated with this regimen is high.
Unfortunately, this combination increases the risk of upper gastrointestinal bleeding. Therefore, most guidelines recommend that patients prescribed aspirin plus clopidogrel should also receive a proton pump inhibitor (PPI) to reduce the risk of gastrointestinal bleeding, e.g., the US guidelines [1] and the German guidelines [2].

In the last two years, pharmacological studies have reported an interaction between clopidogrel and omeprazole. Subjects taking both drugs together showed a reduction in the clopidogrel-induced inhibition of platelet aggregation $[3,4]$.

The pharmacological basis of this phenomenon seems to be the competitive inhibition of cytochrome metabolism, especially CYP P450 2C19 (CYP2C19). Clopidogrel is a pro-drug requiring a two-step oxidation by hepatic cytochromes, including CYP2C19, $3 A / 5,1 A 2,2 B 6$, and $2 C 9$, to generate its active thiol metabolite [5]. The key step in its conversion to the active anti-thrombotic agent is performed by CYP2C19. However, all PPIs are metabolized to inactive metabolites by CYP2C19 or other cytochromes to varying degrees [6, 7]. Polymorphisms of the cytochromes may play important roles in a patient's pharmacological response to clopidogrel treatment and the pharmacological interactions of this drug [8, 9].

Data-bank analyses and retrospective cohort studies [10-13] have demonstrated an increased risk of adverse cardiac events in clopidogrel-treated patients who also take PPIs (mainly omeprazole). However, subgroup analyses of randomized controlled trials [14, $15]$ and other studies $[16,17]$ have not confirmed the adverse effects of PPI co-therapy. Only one randomized controlled study has so far addressed this topic (COGENT). Unfortunately, this trial was stopped early, after the sponsor Cogentus Pharmaceuticals (Palo Alto, CA, USA) declared bankruptcy. The first reports from this study did not show evidence of a clinically relevant drug interaction [18].

Based in this uncertainty, both the US Food and Drug Administration (FDA) and the European Medicines Agency (EMEA) have warned that omeprazole should not be combined with clopidogrel unless "absolutely necessary" (EMEA). The FDA warning also included esomeprazole. These warnings of the FDA 
and EMEA do not resolve, but indeed increase the problem for physicians treating patients who require dual therapies.

Based on their mode of action via the irreversible inhibition of platelet and parietal cell functions, both clopidogrel and PPI are very potent and long-acting drugs. The active metabolite of clopidogrel irreversibly inhibits the platelet adenosine diphosphate (ADP) $\mathrm{P}_{2} \mathrm{Y}_{12}$ receptor through an inactivating disulfide bond, whereas PPIs irreversibly inhibit the proton pumps of parietal cells. However, the plasma half lives of both clopidogrel and PPIs are less than two hours. Therefore, several authors have recommended that the intake of the two drugs be separated to reduce the risk of their interaction [19, 20]. However, no data have yet been published on the efficacy of this regimen in preventing the clinically relevant interaction of PPI and clopidogrel.

Other recommendations have suggested the prescription of a PPI other than omeprazole in combination with clopidogrel [21, 22]. However, few data are so far available on the differences between various PPIs in their potential interactions with clopidogrel activation. Pantoprazole [22-24] and esomeprazole [23, 24] but not lansoprazole [25] seem to have little or no pharmacological effect on the activation of clopidogrel.

We studied the effects of both the separation of omeprazole and clopidogrel intake on platelet inhibition and the use of the PPI rabeprazole in a co-therapy with clopidogrel in four subjects whose CYP2C19 gene sequences were determined.

\section{Material AND Methods}

\section{SUBJECTS}

Four healthy volunteers were studied. The study was conducted in a manner consistent with ethical principles based on the Declaration of Helsinki. Written informed consent was obtained from all study participants before study entry.

\section{Medication and Study Protocol}

After the baseline (day 0) platelet function of all subjects was measured, $75 \mathrm{mg}$ of clopidogrel was given in the morning before breakfast for seven days without an initial loading dose. On day 7, two hours after clopidogrel intake, a blood sample was drawn for the analysis of platelet function, and $20 \mathrm{mg}$ of omeprazole (Antra MUPS, AstraZeneca GmbH, Wedel, Germany) was taken. For the next six days, $75 \mathrm{mg}$ of clopidogrel and $20 \mathrm{mg}$ of omeprazole were taken together before breakfast. After seven days of the combined intake of clopidogrel and omeprazole, another blood sample was taken two hours after the administration of the medication (day 14). For the next seven days, clopidogrel was taken before breakfast and omeprazole was taken before dinner (the intake of the two drugs was separated by 12 hours). A blood sample was taken in the morning after the separated intake of clopidogrel and omeprazole (day 21) for seven days. No omeprazole was taken in the evening of day 21. Starting day 22, the subjects took clopidogrel and 10 mg of rabeprazole together before breakfast. Again, blood was drawn after seven days, two hours after the intake of the medication (day 28).

Study endpoints: Non-responders to clopidogrel were discharged from the study after the first week of clopidogrel intake. Subjects with no reduction in platelet inhibition in response to the co-therapy with clopidogrel and omeprazole were not investigated further.

\section{Aggregometri}

ADP-induced aggregometry is a widely used method of measuring responsiveness to clopidogrel. Wholeblood aggregation was determined with an impedance aggregometer (Multiplate Analyzer, Dynabyte GmbH, Munich, Germany). The system detects the change in electrical impedance attributed to the adhesion and aggregation of platelets on two independent pairs of silver-coated, highly conductive copper wires (length 3.2 $\mathrm{mm}$ ) in the test cuvette. Therefore, two measurements are obtained as an internal control. For the analysis, $300 \mu \mathrm{L}$ of whole blood anti-coagulated with hirudin $(200 \mathrm{U} / \mathrm{mL}$, Dynabyte $\mathrm{GmbH})$ and $300 \mu \mathrm{L}$ of $0.9 \%$ $\mathrm{NaCl}$ was stirred at $37^{\circ} \mathrm{C}$ for $3 \mathrm{~min}$ in a single-use test cuvette, and ADP $(6.4 \mu \mathrm{mol} / \mathrm{L}$; Dynabyte $\mathrm{GmbH})$ was added. Pipetting was performed with an attached electronic pipette. The increase in electrical impedance was recorded continuously for $6 \mathrm{~min}$. The areas under the curves (AUC) of the aggregation tracings are expressed as the mean values of two independent determinations. The results measured with the Multiplate Analyzer were reproducible, with less than 6\% variability [26]. The reference range of the test was 53-122 AUC [U].

\section{GENOTYPING}

DNA was extracted from EDTA blood using the FlexiGene DNA isolation kit (Qiagen, Hilden, Germany). All nine coding exons and the flanking regions of the CYP2C19 gene (GenBank: NT_030059.13) were amplified with a standard PCR, and analysed by direct DNA sequencing with BigDye v1.1 on an ABI Prism 3130 Avant XL (Applied Biosystems, Foster City, CA, USA). To describe the mutations, we applied the nomenclature used by the CYPalleles data base (http://www.cypalleles.ki.se; GenBank M61854.1). The primer sequences are available upon request. The gene sequences were analysed with the software Mutation Surveyor V3.10 (Softgenetics LLC, State College, PA, USA).

\section{RESULTS}

Two subjects were found to carry the wild-type allele (allele *1) of CYP2C19 (subject \#1 and \#2). The other two subjects (\#3 and \#4) were heterozygous for the mutations c.681G $>$ A; p.Pro227Pro, and thus carried the alleles $* 1 / * 2$ (Table 1$)$. No other reduced-function CYP2C19 allele was observed in this study group. Reduced CYP2C19 function was predicted for the subjects with the CYP2C19 wt/*2 genotype $[8,9]$. 
Table 1. Subject characteristics and CYP2C19 allele status

\begin{tabular}{lllll}
\hline Subject & Sex & Age & CYP2C19 alleles & Predicted CYP2C19 function \\
\hline 1 & male & 58 & $\mathrm{wt} / \mathrm{wt}$ & normal \\
2 & male & 51 & $\mathrm{wt} / \mathrm{wt}$ & normal \\
3 & female & 28 & $\mathrm{wt} / * 2$ & reduced \\
4 & female & 32 & $\mathrm{wt} / * 2$ & reduced \\
\hline
\end{tabular}

Table 2. ADP-induced platelet aggregation in four subjects treated with clopidogrel with and without PPI co-therapy. The reference range of the test was 53-122 U.

Clopidogrel intake inhibits ADP-induced platelet aggregation in subjects showing the expected clopidogrel effect. Normal platelet function under clopidogrel mono-therapy represents a non-responder status. The normalization of platelet function by co-therapy with clopidogrel and PPI after platelet function is inhibited by clopidogrel mono-therapy indicates a pharmacologically relevant drug interaction.

\begin{tabular}{|c|c|c|c|c|}
\hline \multirow[t]{2}{*}{ Medication } & \multicolumn{4}{|l|}{ Subjects } \\
\hline & $\# 1$ (wt/wt) & $\# 2$ (wt/wt) & $\# 3(\mathrm{wt} / * 2)$ & $\# 4(\mathrm{wt} / * 2)$ \\
\hline baseline & normal & normal & normal & normal \\
\hline$($ day 0$)$ & $85 \mathrm{U}$ & $79 \mathrm{U}$ & $89 \mathrm{U}$ & $101 \mathrm{U}$ \\
\hline clopidogrel mono-therapy & inhibited & inhibited & normal & inhibited \\
\hline (day 7$)$ & $42 \mathrm{U}$ & $16 \mathrm{U}$ & $97 \mathrm{U}$ & $31 \mathrm{U}$ \\
\hline clopidogrel and omeprazole & inhibited & inhibited & n.s. ${ }^{*}$ & normal \\
\hline taken together (day 14) & $44 \mathrm{U}$ & $10 \mathrm{U}$ & & $74 \mathrm{U}$ \\
\hline clopidogrel and omeprazole & n.s.* & n.s.* & n.s* & normal \\
\hline $\begin{array}{l}\text { clopidogrel and rabeprazole } \\
\text { taken together (dav 28) }\end{array}$ & n.s. ${ }^{*}$ & n.s.* & n.s. ${ }^{*}$ & $\begin{array}{l}\text { inhibited } \\
43 \mathrm{U}\end{array}$ \\
\hline
\end{tabular}

*n.s., not studied, according to protocol.

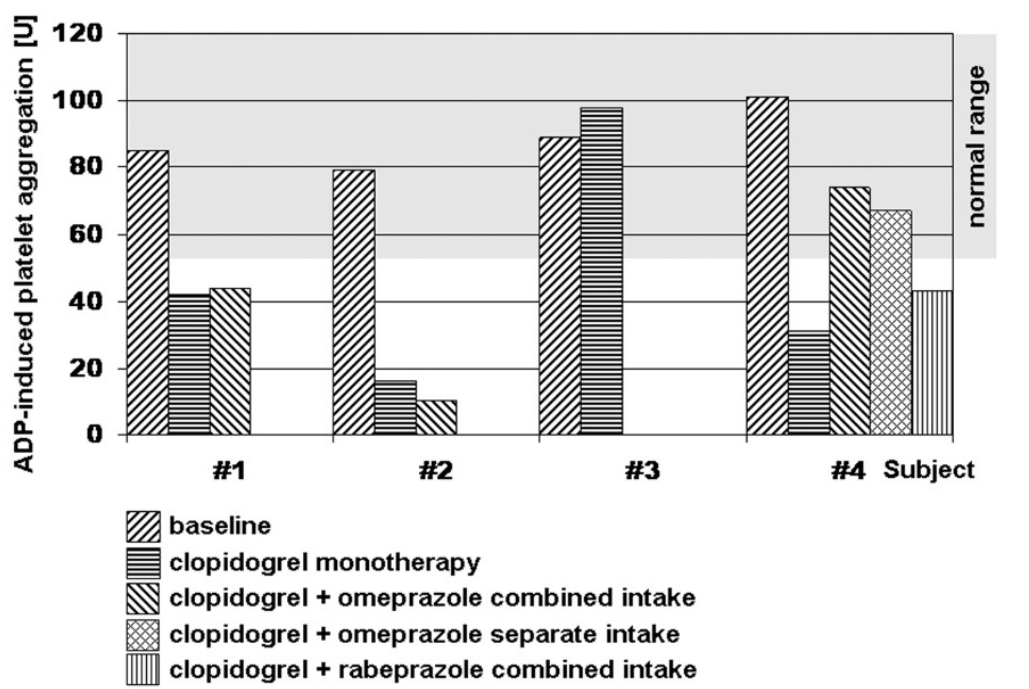

Fig. 1. ADP-induced platelet aggregation in four subjects treated with clopidogrel with and without PPI co-therapy. The reference range of the test was $53-122 \mathrm{U}$.
In subject \#1, the baseline platelet function was normal. The clopidogrel-induced inhibition of platelet function was not influenced by the cotherapy with omeprazole (Table 2, Fig. 1). Therefore, according to the protocol, not further tests were performed.

In subject \#2, the platelet function was inhibited by clopidogrel mono-therapy, and platelet function was normalized when clopidogrel and omeprazole were taken together (value $58 \mathrm{U}$ ). Because the subject suffered from diarrhoea on days 5 and 6 of the combined intake (presumably viral enteritis), this part of the study was repeated after his recovery and no effect of omeprazole co-medication was observed on clopidogrel-induced platelet inhibition $(10 \mathrm{U}$; data shown in Table 2). 
Clopidogrel treatment did not the alter platelet function of subject \#3, indicating a non-responder status. According to the protocol, no further tests were performed.

In subject \#4, co-therapy with omeprazole and clopidogrel normalized platelet function, indicating a relevant drug interaction. This interaction was not abolished by separating the intake of the two drugs. However, when rabeprazole was taken together with clopidogrel, platelet aggregation was inhibited to the range observed during clopidogrel mono-therapy.

\section{DisCUSSION}

Two of the four subjects (\#1 and \#2) carried only the wild-type allele of CYP2C19. For both of them, cotherapy with $20 \mathrm{mg}$ of omeprazole did not diminish the clopidogrel-induced inhibition of platelet aggregation, even when the drugs were taken simultaneously. The clopidogrel-PPI interaction may therefore affect only the subgroup of patients with genetic variants of CYP2C19 and not the three quarters of the white European population who are homozygous for the wildtype CYP2C19 allele [9].

The findings in subject \#2 suggest that an acute episode of diarrhoea may reduce the clopidogrel-induced inhibition of platelet aggregation. The most likely explanation is a reduction in gastrointestinal absorption of clopidogrel. Considering the high incidence of acute viral enteritis and the importance of dual antiplatelet therapy this phenomenon should be studied in more detail.

Subject \#3 was a clopidogrel non-responder, although she carried one wild-type allele. Because about $25 \%$ of the Caucasian population have the same CYP2C19 allele status wt/*2 [9], a large proportion of patients treated with clopidogrel may be non-responders. Therefore, it seems reasonable to test the clopidogrel-responder status of a patient who requires dual anti-platelet therapy rather than genotyping the patient.

Subject \#4 revealed the most important findings. The clopidogrel-omeprazole interaction was observed in this patient with a predicted reduction in CYP2C19 function. Co-therapy with $20 \mathrm{mg}$ of omeprazole completely abolished the clopidogrel-induced inhibition of platelet aggregation. It is reasonable to assume that subjects with reduced CYP2C19 function are at increased risk of this interaction. The interaction was not prevented by separating the intake of the two drugs by 12 hours (clopidogrel in the morning, omeprazole in the evening). However, the simultaneous intake of $10 \mathrm{mg}$ of rabeprazole and clopidogrel did not alter the effect of clopidogrel on platelet function. Although only demonstrated in one subject, this seems to indicate that the interaction between omeprazole and clopidogrel may not be a class effect of PPIs. This was also suggested by other studies [2225].

Rabeprazole was chosen for this study because 10 $\mathrm{mg}$ of this PPI is as potent as $20 \mathrm{mg}$ of omeprazole and more potent than $20 \mathrm{mg}$ of pantoprazole in elevating the intragastric $\mathrm{pH}$ [27]. Conversely, plasma levels of rabeprazole after an intake of $10 \mathrm{mg}$ are lower than those measured after an intake of $20 \mathrm{mg}$ of omeprazole or $20 \mathrm{mg}$ of pantoprazole (these doses are necessary for the prevention of peptic gastrointestinal ulcer), minimizing the risk of a drug interaction with clopidogrel [7].

Although these observations require confirmation in much larger trials, they suggest that clopidogrel should not be combined with omeprazole but with other PPIs, such as rabeprazole, if PPI co-therapy is necessary in patients receiving clopidogrel therapy. This conclusion is consistent with the recommendations of the FDA and EMEA.

Although the separation of the intake of clopidogrel and omeprazole did not affect the interaction in one subject, it is still reasonable to adopt this strategy because it may be beneficial in other subjects. The only possible disadvantage of such separated intake of the two medications is reduced compliance. Therefore, patients must be informed of the importance of taking the medications.

Considering the high prevalence of patients taking clopidogrel and aspirin and the need for gastroprotection, prospective randomized trials with clinical endpoints that examine the safest and most effective drug regimen are highly warranted and should be undertaken in the near future. Until more clinical data are published, the prescription of a non-omeprazole PPI and the separation of drug intake are preferable, although the effect of separating the intake of the drugs is unsubstantiated.

Comment: This study was not supported from any pharmaceutical company and performed without any financial support.

\section{REFERENCES}

1. Bhatt DL, Scheiman J, Abraham NS, Antman EM, Chan FK, Furberg CD, Johnson DA, Mahaffey KW, Quigley EM, Harrington RA, Bates ER, Bridges CR, Eisenberg MJ, Ferrari VA, Hlatky MA, Kaul S, Lindner JR, Moliterno DJ, Mukherjee D, Schofield RS, Rosenson RS, Stein JH, Weitz HH, Wesley DJ, American College of Cardiology Foundation Task Force on Clinical Expert Consensus Documents. ACCF/ACG/AHA 2008 Expert Consensus Document on Reducing the Gastrointestinal Risks of Antiplatelet Therapy and NSAID Use. J Am Coll Cardiol 2008 Oct 28; 52(18): 1502-17.

2. Fischbach W, Malfertheiner P, Hoffmann JC, Bolten W, Bornschein J, Götze O, Höhne W, Kist M, Koletzko S, Labenz J, Layer P, Miehlke S, Morgner A, Peitz U, Preiss J, Prinz C, Rosien U, Schmidt W, Schwarzer A, Suerbaum S, Timmer A, Treiber G, Vieth M. S3-guideline "helicobacter pylori and gastroduodenal ulcer disease" of the German society for digestive and metabolic diseases (DGVS) in cooperation with the German society for hygiene and microbiology, society for pediatric gastroenterology and nutrition e. V., German society for rheumatology. Z Gastroenterol. 2009 Dec; 47(12):1230-63.

3. Gilard M, Arnaud B, Le Gal G, Abgrall JF, Boschat J. Influence of omeprazol on the antiplatelet action of clopidogrel associated to aspirin. J Thromb Haemost. 2006 Nov;4(11):2508-9.

4. Gilard M, Arnaud B, Cornily JC, Le Gal G, Lacut K, Le Calvez G, Mansourati J, Mottier D, Abgrall JF, Boschat J. Influence of omeprazole on the antiplatelet action of clopidogrel associated with aspirin: the randomized, dou- 
ble-blind OCLA (Omeprazole CLopidogrel Aspirin) study. J Am Coll Cardiol. 2008 Jan 22;51(3):256-60.

5. Petersen K-U. Relevance of Metabolic Activator Pathways: The Example of Clopidogrel and Prasugrel. Arzneimittelforschung. 2009; 59(5): 213-27.

6. Ko JW, Sukhova N, Thacker D, Chen P, Flockhart DA. Evaluation of omeprazole and lansoprazole as inhibitors of cytochrome P450 isoforms. Drug Metab Dispos. 1997 Jul;25(7):853-62.

7. Li X-Q, Andersson TB, Ahlström M, Weidolf L: Comparison of inhibitory effects of the proton pump-inhibiting drugs omeprazole, esomeprazole, lansoprazole, pantoprazole, and rabeprazole on human cytochrome P450 activities. Drug Metabolism and Disposition 2004; 232 (8): 821-827

8. Brandt JT, Close SL, Iturria SJ, Payne CD, Farid NA, Ernest CS 2nd, Lachno DR, Salazar D, Winters KJ. Common polymorphisms of CYP2C19 and CYP2C9 affect the pharmacokinetic and pharmacodynamic response to clopidogrel but not prasugrel. J Thromb Haemost. 2007 Dec; 5(12): 2429-36.

9. Collet JP, Hulot JS, Pena A, Villard E, Esteve JB, Silvain J, Payot L, Brugier D, Cayla G, Beygui F, Bensimon G, Funck-Brentano C, Montalescot G. Cytochrome P450 2C19 polymorphism in young patients treated with clopidogrel after myocardial infarction: a cohort study. Lancet. 2009 Jan 24; 373(9660): 309-17

10. Pezalla E, Day D, Pulliadath I. Initial assessment of clinical impact of a drug interaction between clopidogrel and proton pump inhibitors. J Am Coll Cardiol. 2008 Sep 16;52(12):1038-9.

11. Aubert R, Epstein RS, Teagarden JR, Xia F, Yao J, Desta Z, Skaar T, Flockhart DA. Proton pump inhibitors effect on clopidogrel effectiveness: the Clopidogrel Medco Outcomes Study (abstract 3998). Circulation 2008; 118:S815.

12. Ho PM, Maddox TM, Wang L, Fihn SD, Jesse RL, Peterson ED, Rumsfeld JS. Risk of Adverse Outcomes Associated With Concomitant Use of Clopidogrel and Proton Pump Inhibitors Following Acute Coronary Syndrome. JAMA 2009 Mar 4; 301(9): 937-44.

13. Gupta E, Bansal D, Sotos J, Olden K: Risk of adverse clinical outcomes with concomitant use of clopidogrel and proton pump inhibitors following percutaneous coronary intervention. Dig Dis Sci. 2009 Sep 3. [Epub ahead of print]

14. O'Donoghue ML, Braunwald E, Antman EM, Murphy SA, Bates ER, Rozenman Y, Michelson AD, Hautvast RW, Ver Lee PN, Close SL, Shen L, Mega JL, Sabatine MS, Wiviott SD. Pharmacodynamic effect and clinical efficacy of clopidogrel and prasugrel with or without a proton-pump inhibitor: an analysis of two randomised trials. Lancet. 2009 Sep 19; 374(9694): 989-97.

15. Dunn SP, Macaulay TE, Brennan DM, Campbell CL, Charnigo RJ, Smyth SS, Berger PB, Steinhubl SR, Topol EJ. Baseline proton pump inhibitor use is associated with increased cardiovascular events with and without the use of clopidogrel in the CREDO trial. Circulation 2008; 118: S 815 .

16. Simon T, Verstuyft C, Mary-Krause M, Quteineh L, Drouet E, Méneveau N, Steg PG, Ferrières J, Danchin N, Becquemont L, French Registry of Acute ST-Elevation and Non-ST-Elevation Myocardial Infarction (FAST-MI) Investigators. Genetic Determinants of Response to Clopidogrel and Cardiovascular Events. N Engl J Med. 2009 Jan 22; 360(4): 363-75.
17. Zairis MN, Tsiaousis GZ, Patsourakos NG, Georgilas AT, Kontos CF, Adamopoulou EN, Vogiatzidis K, Argyrakis SK, Fakiolas CN, Foussas SG. The impact of treatment with omeprazole on the effectiveness of clopidogrel drug therapy during the first year after successful coronary stenting. Can J Cardiol. 2010 Feb;26(2):e54-7.

18. Depta JP, Bhatt DL. Omeprazole and clopidogrel: Should clinicians be worried? Cleve Clin J Med. 2010 Feb; 77(2): 113-6.

19. Laine L, Hennekens C. Proton pump inhibitor and clopidogrel interaction: fact or fiction? Am J Gastroenterol. 2010 Jan; 105(1): 34-41.

20. Gross M, Petersen K-U. PPI for Dual Therapy with Clopidogrel: To Use or not to Use? Z Gastroenterol. 2010; 48: 420-3

21. Juurlink DN, Gomes T, Ko DT, Szmitko PE, Austin PC, Tu JV, Henry DA, Kopp A, Mamdani MM. A population-based study of the drug interaction between proton pump inhibitors and clopidogrel. CMAJ. 2009 Mar 31;180(7):713-8.

22. Cuisset T, Frere C, Quilici J, Poyet R, Gaborit B, Bali L, Brissy O, Morange PE, Alessi MC, Bonnet JL. Comparison of omeprazole and pantoprazole influence on a high 150-mg clopidogrel maintenance dose the PACA (Proton Pump Inhibitors And Clopidogrel Association) prospective randomized study. J Am Coll Cardiol. 2009 Sep 22; 54(13):1149-53

23. Siller-Matula JM, Spiel AO, Lang IM, Kreiner G, Christ G, Jilma B. Effects of pantoprazole and esomeprazole on platelet inhibition by clopidogrel. Am Heart J. 2009 Jan; 157(1):148.e1-5.

24. Sibbing D, Morath T, Stegherr J, Braun S, Vogt W, Hadamitzky M, Schömig A, Kastrati A, von Beckerath N. Impact of proton pump inhibitors on the antiplatelet effects of clopidogrel. Thromb Haemost 2009 Apr; 101(4):714-19.

25. Small DS, Farid NA, Payne CD, Weerakkody GJ, Li YG, Brandt JT, Salazar DE, Winters KJ. Effects of the proton pump inhibitor lansoprazole on the pharmacokinetics and pharmacodynamics of prasugrel and clopidogrel. J Clin Pharmacol. 2008 Apr;48(4):475-84.

26. Tóth O, Calatzis A, Penz S, Losonczy H, Siess W. Multiple electrode aggregometry: a new device to measure platelet aggregation in whole blood. Thromb Haemost. 2006 Dec; 96(6):781-8.

27. Kirchheiner J, Glatt S, Fuhr U, Klotz U, Meineke I, Seufferlein T, Brockmöller J. Relative potency of protonpump inhibitors-comparison of effects on intragastric pH. Eur J Clin Pharmacol. 2009 Jan; 65(1):19-31.

Received: February 26, 2010 / Accepted: March 29, 2010

Address for correspondence:

Prof. Dr.med. Dr.rer.biol.hum. Manfred Gross

Internistische Klinik Dr. Müller

Am Isarkanal 36

81379 Munich

Germany

Tel.: +49-89-724001100

E-mail: gross@muellerklinik.de 